\title{
Using Whole Genome Sequencing to Investigate a Mock-Outbreak of Carbapenem-Resistant Klebsiella pneumoniae in Real-Time
}

\author{
Sequenciação Total do Genoma Como Ferramenta Para \\ Investigar em Tempo Real um Simulacro de Surto por Klebsiella \\ pneumoniae Resistente aos Carbapenemos
}

Alexandra Sofia SIMÕES ${ }^{1 *}$, Tiago TOURET ${ }^{1 *}$, Nuno Alexandre FARIA², Susana PERES LADEIRO ${ }^{3}$, João COSTA $^{3}$, Soraia BISPO ${ }^{4}$, Mónica SERRANO ${ }^{5}$, Carlos PALOS ${ }^{4}$, Maria MIRAGAIA ${ }^{2}$, Ricardo BASTOS LEITE ${ }^{3}$, Raquel SÁ-LEÃO $\triangle 1^{1}$ Acta Med Port 2022 Jan;35(1):36-41 - https://doi.org/10.20344/amp.15174

\section{ABSTRACT}

Introduction: Healthcare associated infections due to carbapenem-resistant Klebsiella pneumoniae (CRKP) are a major concern in Portuguese hospitals. Whole genome sequencing (WGS) can improve infection control, but this practice is not routinely used by hospital clinical laboratories in Portugal. We simulated the investigation of a CRKP outbreak based on WGS, with the aim of determining, in the minimum possible time, genetic relatedness between CRKP clinical and environmental isolates.

Material and Methods: Ten CRKP clinical isolates routinely obtained in the hospital laboratory were used. Forty environmental samples - from sinks and sink drains of ward rooms - were collected. Environmental samples were plated on selective media and presumptive CRKP colonies were isolated. Total DNA was extracted from all putative CRKP isolates and sequenced. Clonal relatedness was determined by multi-locus sequence typing and core genome single nucleotide polymorphism analysis; the presence of carbapenemase genes was evaluated.

Results: Clinical isolates were characterized in 48 hours: eight strains were confirmed as CRKP, of which six were of ST13 and carried bla $_{\mathrm{KPC}-3}$. Environmental samples results were obtained in six days: eight CRKP were isolated from which five were of ST13 and carried bla $_{\mathrm{KPC}-3}$. Clinical and environmental ST13 isolates were highly related: ten (of 11) isolates differed from each other in $<0.001 \%$ of 2172 367 core nucleotides.

Conclusion: In Portugal, routine use of WGS to improve infection control could thrive through collaborative initiatives between hospitals and research institutes.

Keywords: Carbapenem-Resistant Enterobacteriaceae/genetics; Gene-Environment Interaction; Infection Control; Klebsiella Infections; Klebsiella pneumoniae/genetics; Whole Genome Sequencing

\section{RESUMO}

Introdução: As infeções associadas aos cuidados de saúde por Klebsiella pneumoniae resistente aos carbapenemos (CRKP) são uma preocupação nos hospitais portugueses. A sequenciação total do genoma [whole genome sequencing (WGS)] pode ajudar no controlo de infecção, mas esta prática não é comummente utilizada nos laboratórios clínicos hospitalares em Portugal. O objetivo deste estudo foi simular a investigação de um surto causado por CRKP, utilizando WGS. Pretendia-se testar a utilização desta técnica e determinar, no menor tempo possível, relações genéticas entre estirpes.

Material e Métodos: Foram analisados dez isolados clínicos de CRKP. Foram obtidas quarenta amostras ambientais que foram inoculadas em meio seletivo para isolamento de colónias sugestivas de CRKP e depois sequenciado o DNA total dos isolados presumptivamente identificados como CRKP A relação clonal entre as estirpes foi determinada por multi-locus sequence typing e análise de single nucleotide polymorphisms no genoma core. Foi determinada a presença de genes de carbapenemases.

Resultados: Os isolados clínicos foram caraterizados em 48 horas: oito isolados foram confirmados como CRKP. A maioria pertencia ao ST13 $(n=6)$ e possuía o gene $b_{1} a_{\mathrm{KPC}-3}$. As amostras ambientais foram caraterizadas em seis dias: foram isoladas oito CRKP, das quais cinco eram ST13 e continham o gene $b / a_{\mathrm{KPC}-3^{3}}$ Os isolados ST13 clínicos e ambientais eram muito semelhantes entre si: dez dos 11 isolados diferiam entre si em menos de $0,001 \%$ dos 2172367 nucleótidos core analisados.

Conclusão: Em Portugal, o uso desta técnica em controlo de infecção pode ser implementado através de colaborações entre hospitais e institutos de investigação.

Palavras-chave: Controle de Infecções; Enterobacteriáceas Resistentes a Carbapenémicos/genética; Infecções por Klebsiella; Interação Gene-Ambiente; Klebsiella pneumoniae/genética; Sequenciamento Completo do Genoma

\section{INTRODUCTION}

Klebsiella pneumoniae is a Gram-negative Enterobacteriaceae and a major cause of healthcare associated infections. Carbapenem-resistant K. pneumoniae (CRKP),

in particular, is ranked by the World Health Organization in the Global Priority Pathogens List of Antibiotic-resistant Bacteria as a critical pathogen. ${ }^{1}$ Data from the European

\footnotetext{
* These authors contributed equally

1. Laboratory of Molecular Microbiology of Human Pathogens. Instituto de Tecnologia Química e Biológica António Xavier. Universidade Nova de Lisboa. Oeiras. Portugal.

2. Laboratory of Bacterial Evolution and Molecular Epidemiology. Instituto de Tecnologia Química e Biológica António Xavier. Universidade Nova de Lisboa. Oeiras. Portugal.

3. Unidade de Genoma. Instituto Gulbenkian da Ciência. Oeiras. Portugal.

4. Grupo Coordenador Local do Programa de Prevenção e Controlo de Infeções e de Resistência aos Antimicrobianos. Hospital Beatriz Ângelo. Loures. Portugal.

5. Laboratory of Microbial Development. Instituto de Tecnologia Química e Biológica António Xavier. Universidade Nova de Lisboa. Oeiras. Portugal.

$\triangle$ Autor correspondente: Raquel Sá-Leão. rsaleao@itqb.unl.pt

Recebido: 10 de novembro de 2020 - Aceite: 29 de março de 2021 - First published: 10 de novembro de 2021 - Online issue published: 03 de janeiro de 2022
} Copyright $\odot$ Ordem dos Médicos 2022 
Antimicrobial Resistance Surveillance Network (EARS-Net) documented an increasing trend of infections caused by CRKP in 2014 - 2018 in seven European countries including Portugal. Of concern, it was estimated that, in 2018, the rates of CRKP infections in Portugal reached $11.7 \%$ of all $K$. pneumoniae, exceeding the average prevalence for Europe $(7.5 \%) .^{2-4}$

Transmission of pathogens within the hospital setting is often associated with patient-to-patient and patient-to-staffto-patient contacts. ${ }^{5,6}$ In addition, environmental reservoirs can also play an important role..$^{7,8}$ Sinks and sink drains, for example, have been identified as reservoirs of several bacteria, ${ }^{9-12}$ including carbapenemase-producing Enterobacteriaceae. ${ }^{13,14}$ These findings highlight the importance of screening the hospital environment when investigating the origin and transmission routes of pathogens causing healthcare associated infections.

ONEIDA (An OMICS Network to Prevent and Control Infectious Diseases and Antimicrobial Resistance) is a regional project that aims to be a resource for the benefit of healthcare institutions in the Lisbon area. One of its goals is to collaborate with hospitals to integrate real-time bacterial genotyping, based on whole genome sequencing (WGS), as a tool to improve infection control strategies. While WGS of bacterial pathogens is routinely used to prevent and trace outbreaks in some hospitals worldwide, ${ }^{15-18}$ to our best knowledge, such approach is lacking in Portugal.

Here, we describe a pilot study carried out under the framework of ONEIDA that aimed to simulate the investigation of a CRKP outbreak in a Portuguese hospital using WGS.

\section{MATERIAL AND METHODS \\ Clinical strains}

Ten CRKP isolates collected in a hospital clinical laboratory were provided in pure cultures for the simulacrum of the outbreak.

\section{Environmental samples}

Forty samples were collected from sinks and sink drains of the wards where the CRKP-infected patients were admitted. These were collected using swabs (FloqSwabs, Copan), which were immediately placed into tubes containing $1 \mathrm{~mL}$ of trypticase soy broth with $15 \%$ glycerol. Tubes were placed on ice and transported to the research laboratory within six hours of sampling. In the research laboratory, 50 $\mu \mathrm{L}$ of each sample were streaked on each side of a chromID® CARBA SMART (BioMérieux), chromogenic selective plate which enables: (i) presumptive identification of Klebsiella, Enterobacter, Serratia, and Citrobacter (KESC) based on ß-glucosidase production and (ii) the selective growth of carbapenemase producing Enterobacteriaceae (CPE), including K. pneumoniae carbapenemase (KPC) and metallocarbapenemase producers (on the CARB medium side), or OXA-48-type producers (on the OXA medium side). Plates were incubated in aerobic conditions for 18 - 24 hours at $35^{\circ} \mathrm{C}$. For each plate, up to ten isolated colonies suggestive of CRKP were picked and streaked onto the CARB medium side of CARBA SMART plates in order to obtain pure cultures. For each sample only one pure culture was selected for further characterization.

\section{DNA extraction and whole genome sequencing}

Total DNA was extracted using the MagNA Pure Compact (Roche) automated system. Briefly, for each pure culture, one to three colonies were eluted into $1 \mathrm{~mL}$ of PBS solution; $200 \mu \mathrm{L}$ were transferred into a sample tube containing $200 \mu \mathrm{L}$ of lysis buffer (Roche) and $0.18 \mu \mathrm{g}$ of RNase A (Merck) and incubated for $20 \mathrm{~min}$ at $37^{\circ} \mathrm{C}$. This mix was then used for total bacterial DNA extraction using the MagNA Pure Compact Nucleic Acid Isolation Kit (Roche), according to the manufacturer's instructions. DNA quality was assessed through determination of $A_{260} / A_{280}$ and $A_{260} / A_{230}$ ratios using Nanodrop. DNA quantification was performed using the dsDNA High Sensitivity Qubit kit (ThermoFisher), according to the manufacturer's instructions. Isolates were sequenced using the Illumina NextSeq 500 platform (Illumina) to an expected coverage of 100 -fold using pair-ended (PE) with 150 bp per read.

\section{Quality control and genome assembly}

Quality control of raw reads and genome assembly was done using INNUca pipeline v3.1 (https://github.com/B-UMMI/INNUca) under default parameters.

Taxonomic identification, multilocus sequence typing (MLST), core genome tree construction and detection of carbapenemase genes

Bacterial species, genotyping through MLST, core genome tree construction, and the presence of carbapenemase genes were determined using Pathogenwatch (https://pathogen.watch/). Core-single nucleotide polymorphisms (SNPs) were defined based on 1972 genes and 2 172367 nucleotides, and based on these, a phylogenetic tree was constructed, and a difference matrix was obtained.

\section{Ethics}

The study was conducted in accordance with the European Statements for Good Clinical Practice and the declaration of Helsinki of the World Health Medical Association and is integrated in ONEIDA project that was approved by the board of the participating hospital. All samples were numerically coded at the time of sample collection and processed anonymously thereafter.

\section{RESULTS}

For this pilot study, ten clinical isolates identified by the hospital microbiology laboratory as CRKP were received in pure culture and 40 unprocessed environmental samples were received in frozen tubes containing the original swab submerged in liquid medium.

The total DNA of the ten clinical isolates was extracted, whole genome sequenced, and results were analyzed and communicated to the hospital within 48 hours (Fig. 1). 
Environmental samples

Day 1

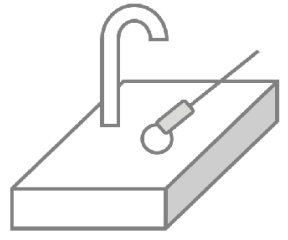

Samples collected $(n=40)$

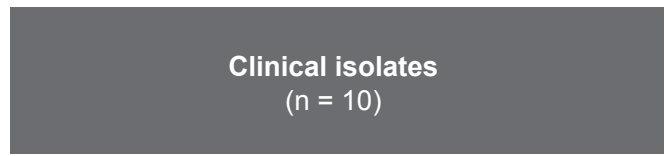

Day 1

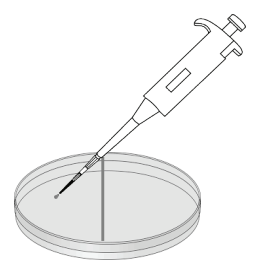

Swabs plated in selective media

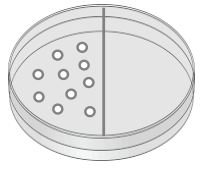

Pure cultures sent to research laboratory

Days 2, 3 and 4

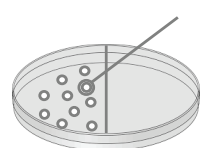

Isolation of colonies suggestive of CRKP

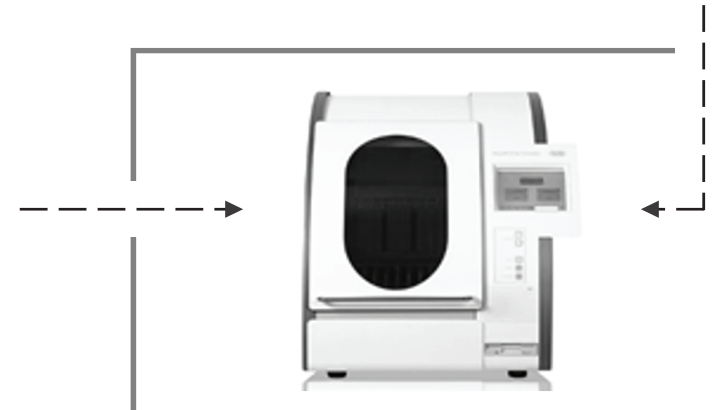

DNA extraction
48 hours

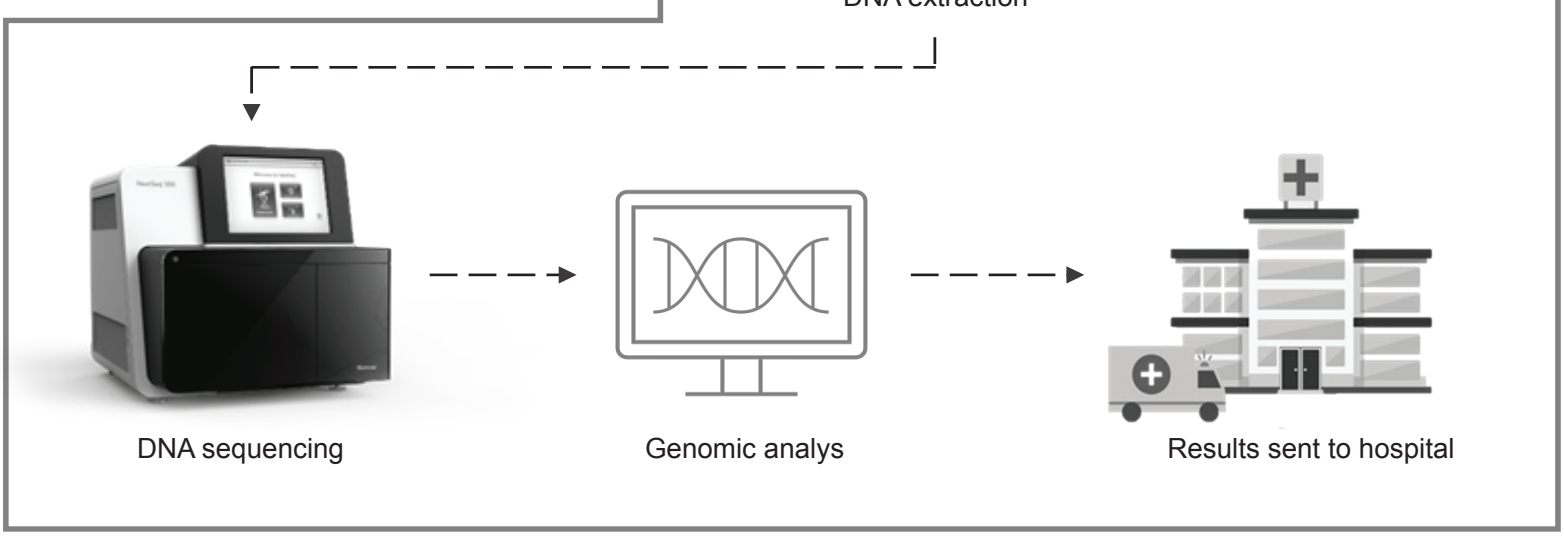

Figure 1 - Timeline of the investigation of a mock-outbreak CRKP: carbapenem-resistant Klebsiella pneumoniae

This included confirmation of species, evaluation of genetic relatedness among strains, and detection of carbapenem resistance determinants.

The results confirmed that eight clinical isolates were CRKP as indicated by the hospital. Two isolates, however, were Klebsiella aerogenes. MLST of the eight CRKP identified three clones: ST13 $(n=6)$, ST14 $(n=1)$ and ST111 $(n=$ $1)$. All isolates of ST13 harbored the bla $a_{\mathrm{KPC}-3}$ gene. Isolates of ST14 and ST111 harbored the bla ${ }_{\text {OXA-181 }}$ gene (Table 1).

Environmental samples took longer to process as culture and isolation of presumptive CRKP had first to be done. This took four extra days compared to the clinical isolates. In total, sample collection, culture isolation, DNA extraction, sequencing, analysis and communication of results took six days (Fig. 1).

Among the 40 environmental samples, nineteen (three from sinks and 16 from sink drains) yielded colonies compatible with KESC in the selective media. Pure cultures of the 19 colonies were grown, DNA was extracted and whole genome sequencing was carried out (Fig. 1). The nucleotide raw reads of one isolate did not pass quality control (OND468) and were not analyzed. Among the remaining eighteen isolates, eight were confirmed as CRKP and ten belonged to other species: Enterobacter kobei $(n=5)$, Aeromonas hydrophila $(\mathrm{n}=1)$, Citrobacter freundii $(\mathrm{n}=1)$, Klebsiella oxytoca $(n=1)$, Raoultella ornithinolytica $(n=1)$ and Serratia marcescens $(n=1)$. The medium coverage obtained after assembly of the eighteen isolates was 54 -fold.

Six of the eight of CRKP environmental isolates were recovered from sink drains. MLST identified three clones: ST13 $(n=5)$, ST323 $(n=2)$ and ST147 $(n=1)$. All environmental CRKP isolates harbored the $b / a_{\mathrm{KPC} 3}$ gene. 
Table 1 - Characteristics of clinical isolates

\begin{tabular}{|c|c|c|c|}
\hline \multirow{2}{*}{ Sample ID } & \multicolumn{3}{|c|}{ WGS results } \\
\hline & Species & ST & Carbapenemase genes \\
\hline OND451 & Klebsiella pneumoniae & 13 & $b / a_{\mathrm{KPC}-3}$ \\
\hline OND452 & Klebsiella pneumoniae & 111 & $b_{\text {OXA-181 }}$ \\
\hline OND453 & Klebsiella aerogenes & - & - \\
\hline OND454 & Klebsiella pneumoniae & 14 & $b / a_{\text {OXA-181 }}$ \\
\hline OND455 & Klebsiella pneumoniae & 13 & $b / a_{\mathrm{KPC}-3}$ \\
\hline OND456 & Klebsiella pneumoniae & 13 & $b / a_{\mathrm{KPC}-3}$ \\
\hline OND457 & Klebsiella pneumoniae & 13 & $b / a_{\mathrm{KPC}-3}$ \\
\hline OND458 & Klebsiella pneumoniae & 13 & $b / a_{\mathrm{KPC}-3}$ \\
\hline OND459 & Klebsiella aerogenes & - & - \\
\hline OND460 & Klebsiella pneumoniae & 13 & $b / a_{\mathrm{KPC}-3}$ \\
\hline
\end{tabular}

ST: sequence type

Table 2 - Characteristics of environmental samples with colonies suggestive of CRKP

\begin{tabular}{|c|c|c|c|c|c|}
\hline \multirow{2}{*}{ Stample ID } & \multirow{2}{*}{ Isolation site } & \multirow{2}{*}{$\begin{array}{c}\text { Colonies suggestive } \\
\text { of CRKP? }\end{array}$} & \multicolumn{3}{|c|}{ WGS results } \\
\hline & & & Species & ST & Carbapenemase genes \\
\hline OND462 & sink drain & yes & Klebsiella oxytoca & nd & nd \\
\hline OND463 & sink drain & yes & Enterobacter kobei & nd & nd \\
\hline OND466 & sink drain & yes & Klebsiella pneumoniae & 13 & $b / a_{\mathrm{KPC}-3}$ \\
\hline OND467 & sink & yes & Enterobacter kobei & nd & nd \\
\hline OND470 & sink drain & yes & Enterobacter kobei & nd & nd \\
\hline OND472 & sink drain & yes & Aeromonas hydrophila & nd & nd \\
\hline OND474 & sink drain & yes & Raoultella ornithinolytica & nd & nd \\
\hline OND482 & sink drain & yes & Klebsiella pneumoniae & 147 & $b / a_{\mathrm{KPC}-3} ; b l a_{\mathrm{GES}-5}$ \\
\hline OND484 & sink drain & yes & Enterobacter kobei & nd & nd \\
\hline OND486 & sink drain & yes & Serratia marcescens & nd & nd \\
\hline OND488 & sink drain & yes & Citrobacter freundii & nd & nd \\
\hline OND490 & sink drain & yes & Klebsiella pneumoniae & 13 & $b l a_{\mathrm{KPC}-3}$ \\
\hline OND493 & sink & yes & Klebsiella pneumoniae & 323 & $b l a_{\mathrm{KPC}-3}$ \\
\hline OND494 & sink drain & yes & Klebsiella pneumoniae & 323 & $b l a_{\mathrm{KPC}-3}$ \\
\hline OND495 & sink & yes & Klebsiella pneumoniae & 13 & $b / a_{\mathrm{KPC}-3}$ \\
\hline OND496 & sink drain & yes & Enterobacter kobei & nd & nd \\
\hline OND498 & sink drain & yes & Klebsiella pneumoniae & 13 & $b l a_{\mathrm{KPC}-3}$ \\
\hline OND500 & sink drain & yes & Klebsiella pneumoniae & 13 & $b / a_{\mathrm{KPC}-3}$ \\
\hline
\end{tabular}

ST: sequence type; CRKP: carbapenem-resistant Klebsiella pneumoniae; nd: not determined

The ST147 isolate also harbored the bla ${ }_{\text {GES-5 }}$ gene (Table 2).

\section{Core genome SNP clustering of all CRKP isolates}

A core genome distance-based neighbor-joining tree based on core SNP data was constructed for all CRKP isolates - eight clinical and eight environmental - and the results are summarized in Fig. 2. This analysis was particularly important to evaluate whether isolates sharing the same sequence type were closely related (i.e., differed in a very small number of core nucleotides) and thus crosstransmission might have occurred very recently in time. Alternatively, isolates sharing the same sequence type but differing in several core nucleotides might reflect dissemination of an endemic clone.
Comparison of the 11 isolates (six clinical, five environmental) of ST13, revealed that ten differed from each other in 0-19 nucleotides and, of these, eight had less than six nucleotide differences between them. Notably, isolates OND458 (clinical) and OND498 (environmental) had no nucleotide differences between them. On the other hand, one isolate (OND490) differed in 124 nucleotides or more from all the other ST13 isolates (Appendix 1: https://www. actamedicaportuguesa.com/revista/index.php/amp/article/ view/15174/Appendix_01.pdf).

\section{DISCUSSION}

We simulated the investigation of a CRKP outbreak in a Portuguese hospital, using approaches based on WGS. 


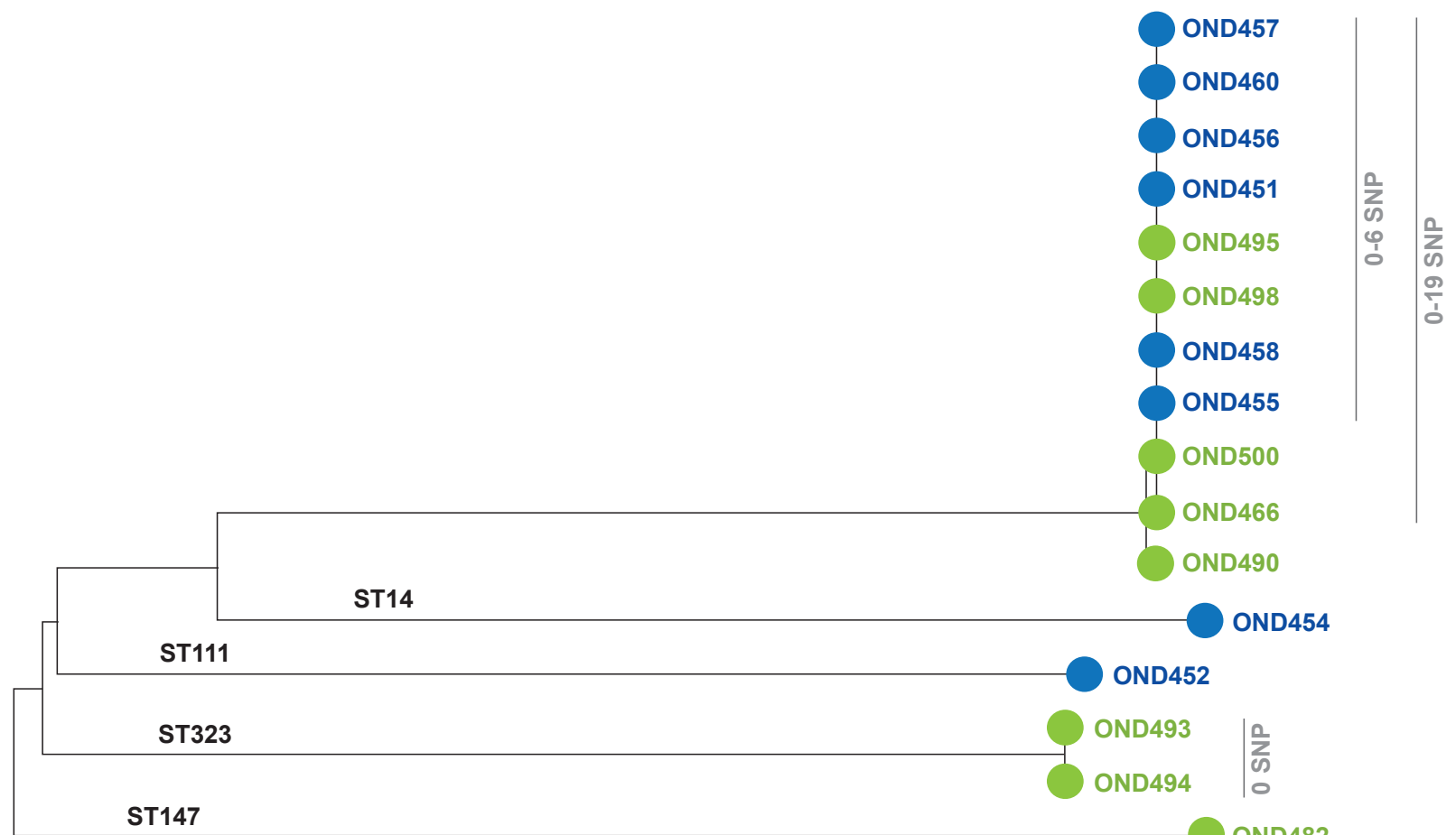

865

Figure 2 - Core genome distance-based neighbor-joining tree based on core-SNP data of all carbapenem-resistant Klebsiella pneumoniae isolated

Blue, clinical isolates; green, environmental isolates; ST: sequence type; SNP: core-single nucleotide polymorphism

Our specific goals were to determine, in the minimum possible time, (i) whether environmental samples contained CRKP and (ii) the genetic relatedness between CRKP clinical and environmental isolates.

The results regarding similarity of clinical isolates were communicated to the hospital within 48 hours. The results regarding the presence of CRKP in environmental samples and its similarity to other CRKP were obtained within six days. Both results were thus obtained within a reasonable time needed for an infection control team to understand how to best tackle a sudden increase of healthcare associated infections due to CRKP.

This study has a major limitation. Only one colony per environmental sample was studied, preventing eventual identification of additional CRKP from these type of samples.

On the other hand, our results support the use of WGS as a high-resolution effective tool to investigate healthcare associated infections and track routes of dissemination in real-time. We advocate that, in Portugal, routine use of such approaches could thrive through collaborative initiatives between hospitals and research institutes. Although the costs associated with WGS of bacterial pathogens are considered high to be used on a routine basis in Portugal for hospital surveillance, they allow for rapid decision-making and implementation of targeted infection control measures. Such actions are crucial to prevent hospital-acquired infections and offset the health and economic costs associated with it. To increase immediate cost-effectiveness, in future studies, the use of matrix assisted laser desorption ionization - time of flight, (MALDITOF) which is available in several hospital laboratories), should be considered for the confirmation of species assignment before DNA extraction and WGS.

This pilot study demonstrated the ability to investigate an outbreak in real time through WGS. The results further indicate that concomitant environmental sampling is informative to determine transmission routes, allowing for rapid decision-making. Collaborative partnerships between hospitals and research institutes should be fostered to accelerate introduction of WGS as an effective tool to support infection control teams.

\section{CONCLUSION}

This pilot study highlights the importance of collaborative partnerships between hospitals and research institutes to accelerate and/or introduce effective tools to support healthcare workers in infection control.

\section{AUTHORS CONTRIBUTION}

ASS: Conception of the study; environment sample collection; analysis of the results; draft and critical review of the manuscript.

TT: Conception of the study; sample processing; analysis of the results; draft and critical review of the manuscript. 
NAF: Conception of the study; sample processing; analysis of the results; critical review of the manuscript.

SPL, JC: Sample processing; critical review of the manuscript.

SB: Conception of the study; environment sample collection; critical review of the manuscript.

MS, CP, RBL: Conception of the study; critical review of the manuscript.

MM: Conception of the study; analysis of the results; critical review of the manuscript.

RSL: Conception of the study; analysis of the results; draft and critical review of the manuscript.

\section{PROTECTION OF HUMANS AND ANIMALS}

The authors declare that the procedures were followed according to the regulations established by the Clinical Research and Ethics Committee and to the Helsinki Declaration of the World Medical Association updated in 2013.

\section{DATA CONFIDENTIALITY}

The authors declare having followed the protocols in use at their working center regarding patients' data publication.

\section{COMPETING INTERESTS}

The authors report no conflicts of interest.

\section{FUNDING SOURCES}

Fundação para a Ciência e a Tecnologia (FCT) project UID/DTP/04567/2016. This work was financially supported by projects LISBOA-01-0145-FEDER (Microbiologia Molecular, Estrutural e Celular, funded by FEDER through COMPETE2020 - Programa Operacional Competitividade e Internacionalização) and LISBOA-01-0145-FEDER-016417 [ONEIDA co-funded by Fundos Europeus Estruturais e de Investimento, Programa Operacional Regional Lisboa 2020 and Fundação para a Ciência e a Tecnologia (FCT)].

\section{REFERENCES}

1. World Health Organization. Global priority list of antibiotic-resistant bacteria to guide research, discovery, and development of new antibiotics. Geneva: WHO; 2017.

2. Rodrigues M, Lebre A, Alves A, Félix AM, Tavares D, Noriega E, et al. Infeções e resistências aos antimicrobianos: relatório anual do programa prioritário 2018. Lisboa: Direção-Geral da Saúde; 2018.

3. European Centre for Disease Prevention and Control. Surveillance of antimicrobial resistance in Europe 2017. Stockholm: ECDC; 2018.

4. European Centre for Disease Prevention and Control. Surveillance of antimicrobial resistance in Europe 2018. Stockholm: ECDC; 2019.

5. Danzmann L, Gastmeier P, Schwab F, Vonberg R. Health care workers causing large nosocomial outbreaks: a systematic review. BMC Infect Dis. 2013;13:1

6. Grundmann H, Bärwolff S, Tami A, Behnke M, Schwab F, Geffers C, et al. How many infections are caused by patient-to-patient transmission in intensive care units? Crit Care Med. 2005;33:946-51.

7. Boyce J. Environmental contamination makes an important contribution to hospital infection. J Hosp Infect. 2007;65:50-4.

8. Weber D, Rutala W, Miller M, Huslage K, Sickbert-Bennett E. Role of hospital surfaces in the transmission of emerging health care-associated pathogens: Norovirus, Clostridium difficile, and Acinetobacter species. Am J Infect Control. 2010;38:S25-33.

9. Lowe C, Willey B, O'Shaughnessy A, Lee W, Lum M, Pike K, et al. Outbreak of extended-spectrum $\beta$-lactamase-producing Klebsiella oxytoca infections associated with contaminated handwashing sinks. Emerg Infect Dis. 2012;18:1242-7.

10. Starlander G, Melhus $\AA$. Minor outbreak of extended-spectrum $\beta$-lactamase-producing Klebsiella pneumoniae in an intensive care unit due to a contaminated sink. J Hosp Infect. 2012;82:122-4.

11. Hopman J, Meijer C, Kenters N, Coolen JP, Ghamati MR, Mehtar S, et al. Risk assessment after a severe hospital-acquired infection associated with carbapenemase-producing Pseudomonas aeruginosa. JAMA Netw Open. 2019;2 :e187665.

12. Gordon A, Mathers A, Cheong E, Gottlieb T, Kotay S, Walker A, et al. The hospital water environment as a reservoir for carbapenem-resistant organisms causing hospital-acquired infections - a systematic review of the literature. Clin Infect Dis. 2017;64:1435-44.

13. Smismans A, Ho E, Daniels D, Ombelet S, Mellaerts B, Obbels D, et al. New environmental reservoir of CPE in hospitals. Lancet Infect Dis. 2019;19:580-1.

14. De Geyter D, Blommaert L, Verbraeken N, Sevenois M, Huyghens $\mathrm{L}$, Martini $\mathrm{H}$, et al. The sink as a potential source of transmission of carbapenemase-producing Enterobacteriaceae in the intensive care unit. Antimicrob Resist Infect Control. 2017;6:24.

15. Köser C, Ellington M, Cartwright E, Gillespie S, Brown N, Farrington M, et al. Routine use of microbial whole genome sequencing in diagnostic and public health microbiology. PLoS Pathog. 2012;8:e1002824.

16. Snitkin E, Zelazny A, Thomas P, Stock F, Henderson D, Palmore T, et al. Tracking a hospital outbreak of carbapenem-resistant Klebsiella pneumoniae with whole-genome sequencing. Sci Transl Med. 2012;4:148ra116.

17. David S, Reuter S, Harris SR, Glasner C, Feltwell T, Argimon S, et al Epidemic of carbapenem-resistant Klebsiella pneumoniae in Europe is driven by nosocomial spread. Nat Microbiol. 2019;4:1919-29.

18. Roberts L, Harris P, Ben Zakour N, Forde B, Catchpoole E, StantonCook $\mathrm{M}$, et al. Integrating multiple genomic technologies to investigate an outbreak of carbapenemase-producing Enterobacter hormaechei. Nat Commun. 2020;11:466. 